\title{
The incidence of Down's syndrome in Nigeria
}

\section{A A ADEYOKUNNU}

From the Haematology/Genetic Unit, Department of Paediatrics, College of Medicine, University College Hospital, Ibadan, Nigeria

SUMMARY Studies of Down's syndrome covering a period of 9 years revealed an incidence of 1 in 865 livebirths in a Nigerian hospital. Cytogenetic analysis in 386 patients showed $369(95 \cdot 5 \%)$ cases to be the result of regular trisomy 21 , and translocation trisomy 21 was found in nine $(2 \cdot 5 \%)$ patients. Six $(1.5 \%)$ patients were mosaics and the remaining two $(0.5 \%)$ cases were classified as miscellaneous. A high incidence of cases among young mothers was recorded, but a search for environmental factors contributory to non-disjunction in this relatively young age group was unrevealing. The study has shown that Down's syndrome occurs as commonly in Negroes as in other races. Epidemiological studies like this are necessary to heighten the awareness of health planners in communities that have for a long time considered haemoglobinopathies to be the major genetic disorder, in order to prepare the ground for preventive measures.

Medical reports some 30 years ago ${ }^{1-3}$ suggested the rarity or non-existence of Down's syndrome among Africans. However, between 1955 and 1961 isolated cases were reported from different parts of the continent. ${ }^{4-6}$ Attempts to study the incidence of the syndrome within a given community in Africa gave results contradictory to individual clinical observations. The 1958 WHO collaborative study of congenital malformations, ${ }^{7}$ for example, recorded no case of Down's syndrome in Alexandria, Egypt, or in the Cape coloured community in South Africa. Out of 2068 consecutive deliveries studied by Simpkiss and Lowe in Uganda, ${ }^{8}$ only one case of Down's syndrome was recorded. Yet from the same institution, Luder and Musoke ${ }^{4}$ in 1955 and Leather and Leather ${ }^{5}$ in 1957 reported five and one cases, respectively. Hassan, ${ }^{9}$ working in Sudan, reported 30 cases in 1962. Gupta ${ }^{10}$ working in Ibadan, West Africa only recorded one case in 1969 among 4220 consecutive deliveries. She, however, pointed out that the finding of one case was not in keeping with her clinical observations. Earlier in 1958 Macgregor, ${ }^{6}$ working in the same hospital, collected ten cases in one year. Tompkins, ${ }^{11}$ working in another hospital in Ibadan, documented two cases on whom chromosomal studies were undertaken. Seven years after Gupta's study, ${ }^{10}$ Boroffice ${ }^{12}$ analysed 58 cases in Ibadan. Thus, it would appear from these various reports going back 30 years that the syndrome is not

* Presented at the 6th International Congress of Human Genetics, Jerusalem, Israel, 14 September 1981.

Received for publication 9 October 1981. rare among Africans. Its apparent low incidence might be the result of incomplete ascertainment at birth, high mortality in infancy, and short periods of case collection.

The desire to assess the true incidence of the syndrome in our community prompted the present study. The present communication reports the incidence of the syndrome among livebirths at the University College Hospital, Ibadan, Nigeria during a 9-year period (April 1972 to December 1980). The communication also includes other cases of Down's syndrome referred to the hospital during the period of study.

\section{Materials and methods}

The University College Hospital, Ibadan, is Nigeria's foremost teaching hospital, situated in the southwestern part of the country and inhabited by the Yorubas who claim ancestory from north-east Africa along Sudan. However, they are essentially Africans of Negro stock. The hospital is well staffed by trained medical personnel. Admission to the hospital can only be said to be partially selective and serves an estimated population of 2 to 3 millions.

The obstetric unit of the hospital handles about 3000 deliveries a year. All newborn babies are, at birth, examined by any of the following medical personnel: midwives, nurses, medical students, and physicians. Records are kept of all livebirths, stillbirths, and neonatal deaths. It is not always possible for the paediatrician to see and examine all 
TABLE 1 Age distribution of mothers delivered in some hospitals and rural communities in western Nigeria

\begin{tabular}{|c|c|c|c|c|}
\hline & \multirow{2}{*}{$\begin{array}{l}\text { No of } \\
\text { women }\end{array}$} & \multicolumn{3}{|l|}{ Ages } \\
\hline & & $\begin{array}{l}15-24 \\
(\%)\end{array}$ & $\begin{array}{l}25-34 \\
(\%)\end{array}$ & $\begin{array}{l}35 \text { and over } \\
(\%)\end{array}$ \\
\hline $\begin{array}{l}\text { Igboora } \\
\text { Ibadan }\end{array}$ & 3076 & 30 & 61 & 9 \\
\hline $\begin{array}{l}\text { Adeoyo Hospital } \\
\text { UCH }\end{array}$ & $\begin{array}{l}7119 \\
1944\end{array}$ & $\begin{array}{l}46 \\
31\end{array}$ & $\begin{array}{l}48 \\
56\end{array}$ & $\begin{array}{r}6 \\
13\end{array}$ \\
\hline
\end{tabular}

the stillbirths nor to have necropsies carried out on them all. Mothers and their newborn babies are also examined by an obstetrician 6 weeks after birth.

Babies suspected of having Down's syndrome or any other congenital abnormalities are referred to a paediatrician. Details recorded for such babies include parental age, occupation, place at time of conception, birth order, state of health during pregnancy, history of drug ingestion or exposure to $x$-rays, reason for referral to the $\mathrm{UCH}$, mode of delivery, condition of the baby immediately after delivery, date and month of delivery, and findings of physical examination.

Similar records were made of all other cases of Down's syndrome not delivered in the UCH but referred because of congenital abnormality to the genetic clinic of the Department of Paediatrics.

It was impossible to get accurate records of maternal age for all deliveries since the majority of the mothers, being illiterate, were often ignorant of their correct ages and the semi-educated ones were, for undisclosed reasons, reluctant to give their true ages. Maternal age sampling conducted between April and October 1974 on 800 single deliveries did not show any significant deviation from the work of Platt, ${ }^{13}$ Gupta $^{10}$ and Nylander ${ }^{14}$ (table 1). Reliance was placed on their different data for working out births in different age groups.

Cytogenetic studies were carried out on all the subjects. Standard cytogenetic techniques were used

TABLE 2 Annual frequency of Down's syndrome among 25026 livebirths

\begin{tabular}{lccccc}
\hline Year & Livebirths & Stillbirths & No of cases & $\begin{array}{l}\text { Frequency per } \\
\text { livebirth }\end{array}$ \\
\hline 1972 & 2257 & 93 & 2 & $(-)$ & 1 in 1129 \\
1973 & 2836 & 118 & 4 & $(3)$ & 1 in 709 \\
1974 & 2294 & 134 & 3 & $(1)$ & 1 in 767 \\
1975 & 2808 & 152 & 4 & $(1)$ & 1 in 702 \\
1976 & 3237 & 131 & 3 & $(2)$ & 1 in 1079 \\
1977 & 3190 & 132 & 4 & $(1)$ & 1 in 798 \\
1978 & 3227 & 161 & 4 & $(1)$ & 1 in 807 \\
1979 & 2769 & 134 & 3 & $(2)$ & 1 in 923 \\
1980 & 2408 & 119 & 2 & $(1)$ & 1 in 1204 \\
Total & 25026 & 1081 & 29 & $(12)$ & 1 in 863 \\
\hline
\end{tabular}

No of females in parentheses.
TABLE 3 Specific maternal age in relation to the 29 cases of Down's syndrome ascertained

\begin{tabular}{lcc}
\hline Age $(y r)$ & No of cases & $\%$ of total \\
\hline$<15$ & 1 & $3 \cdot 45$ \\
$15-20$ & 3 & $10 \cdot 34$ \\
$21-25$ & 2 & $6 \cdot 90$ \\
$26-30$ & 11 & $37 \cdot 93$ \\
$31-35$ & 6 & $20 \cdot 69$ \\
$36-40$ & 4 & $13 \cdot 79$ \\
41 plus & 2 & $6 \cdot 90$ \\
Total & 29 & $100 \cdot 00$ \\
\hline
\end{tabular}

and Giemsa banding techniques identified the chromosomes involved in all translocations.

\section{Results}

There were 29 cases of Down's syndrome $(17$ males and 12 females) during the 9-year period. The total number of livebirths during the same period was 25 025, giving an incidence of Down's syndrome of 1 in 863 livebirths (table 2).

The distribution of Down's syndrome births according to maternal age is shown in table 3. Six $(20.69 \%)$ of the 29 cases were born to mothers aged 25 and under. Seventeen $(58.6 \%)$ cases were from mothers aged between 26 and 35, and the remaining six $(20.69 \%)$ were born to mothers aged 35 and over. It should be noted that 30 to $46 \%, 48$ to $61 \%$, and 6 to $13 \%$ of births in this community are to mothers aged 25 or less, 26 to 35 , and 35 and over, respectively (table 1). The mean maternal age of Down's syndrome births during the period of study was 28.06 years. The distribution of maternal age in 386 cases of the syndrome on whom cytogenetic studies were undertaken is shown in table 4. The mean maternal age was 29.3 years. As the majority of the fathers did not turn up for interview, paternal ages could not be correlated with maternal ages.

Cases were seen throughout the year and no statistically significant variations were found in monthly, seasonal, or annual incidence.

In $39 \%$ of cases, the patient was the fifth child, the fourth in $28 \%$, the third in $19 \%$, the second in $3.5 \%$,

TABLE 4 Distribution of maternal age in 386 cases of Down's syndrome

\begin{tabular}{lcc}
\hline Age $(y r)$ & No of cases & Distribution $(\%)$ \\
\hline$<15$ & 6 & $1 \cdot 56$ \\
$15-20$ & 22 & $5 \cdot 70$ \\
$21-25$ & 41 & $10 \cdot 62$ \\
$26-30$ & 148 & $38 \cdot 34$ \\
$31-35$ & 87 & $22 \cdot 54$ \\
$36-40$ & 69 & $17 \cdot 88$ \\
41 plus & 13 & $3 \cdot 36$ \\
Total & 386 & $100 \cdot 00$ \\
\hline
\end{tabular}


and the first born in $1.5 \%$. In $9 \%$ the mother had had six or more previous deliveries.

Trisomy 21 , occurring as a result of nondisjunction, was found in $369(95.5 \%)$ cases and translocation trisomy 21 in nine $(2.5 \%)$ cases. Six $(1.5 \%)$ patients were mosaics and the remaining two $(0.5 \%)$ cases were classified as miscellaneous. Six of the nine cases of translocation involved two $\mathrm{G}$ group chromosomes, while the remainder were $D ; G$ translocations. Cytogenetic studies on all parents of translocation children showed six $G ; G$ sporadic translocations and three familial $D ; G$ translocations, all of maternal origin.

\section{Discussion}

The incidence of Down's syndrome of 1 in 865 livebirths in the present study is similar to the incidence reported from other parts of the world. ${ }^{15-18}$ Compared with the findings of Lesi ${ }^{19}$ in Nigeria 15 years ago, our results show an incidence that is five times higher. This disparity could be due to the length of the present study, which covered 9 years, compared to that of Lesi which covered one year. Cyclical variation in the incidence of the syndrome is well known. ${ }^{20-22}$ Previous workers' explanations of the apparent rarity or non-existence of Down's syndrome among Africans included early marriage and therefore motherhood at a younger age. ${ }^{348}$ Yet, in the present study, the incidence was high among young mothers with a mean maternal age of 28 years. If early maternity acted as a preventive measure against the birth of Down's babies, it is hard to explain what in the environment now induces nondisjunction at a relatively young age. No epidemic occurred in Nigeria during the period of the study, except for a short-lived cholera episode in 1971. There was no statistically significant variation in monthly, seasonal, or annual distribution of the cases.

Cytogenetic analysis of the present cases has confirmed the findings of previous workers. ${ }^{15} 1723$ Of clinically recognisable cases of Down's syndrome, $95 \%$ were trisomic, $4 \%$ had a translocation, and $1 \%$ were mosaics.

It may be concluded that, contrary to early beliefs, Down's syndrome occurs as commonly in the Negro race as in other races. The environmental factors which induce non-disjunction at a relatively young age require further study. Although there is no specific treatment for patients with Down's syndrome, who are invariably mentally retarded, epidemiological studies will heighten the awareness of health planners in a community that has for a long time believed that all its genetic ills are limited to the haemoglobinopathies and allied disorders.

\section{References}

1 Tooth G. Studies in mental illness in the Gold Coast. Colonial Research Publication Series No 6. London: HMSO, 1950.

2 Jellife DB. Aetiology of mongolism. Lancet 1954;ii:871.

3 Jellife DB. Mongolism in Jamaican children. West Indian Med $J$ 1954;3:164-5.

4 Luder J, Musoke LK. Mongolism in Africans. Arch Dis Child 1955;30:310-5.

5 Leather CM, Leather HM. An African mongol. East Afr Med J 1957;34:589-92.

6 Macgregor M. Paediatrics in Western Nigeria. Arch Dis Child 1958;33:277-91.

7 Carter CO. Congenital malformations. WHO Chron 1967;21:287-92.

8 Simpkiss M, Lowe A. Congenital abnormalities in the African newborn. Arch Dis Child 1961;36:404-6.

9 Hassan MM. Mongolism in Sudanese children. J Trop Pediatr 1962;8:48-50.

10 Gupta B. Incidence of congenital malformations in Nigerian children. West Afr Med J 1969;11:22-5.

11 Tompkins AB. Down's syndrome in Nigerian children. J Med Genet 1964;1:115-7.

12 Boroffice RA. Chromosomal studies of 58 cases of Down's syndrome in Nigeria: type and frequency of chromosomal aberrations. Niger Med J 1977;7:323-9.

13 Platt H. Research data. Obstetric records, UCH Ibadan, 1964:14,18-9.

14 Nylander PPS. Maternal age and parity distribution in rural and urban communities in Western Nigeria. Afr $J$ Med Sci 1970;1:285-9.

15 Mikkelsen M, Fischer G, Stene J, Stene E, Petersen E. Incidence of Down's syndrome in Copenhagen, 19601971: with chromosome investigation. Ann Hum Genet 1976;40: 177-82.

16 Evans JA, Hunter AGW, Hamerton JL. Down syndrome and recent demographic trends in Manitoba. J Med Genet 1978;15:43-7.

17 Mulcahy MT. Down's syndrome in Western Australia: cytogenetics and incidence. Hum Genet 1979;48:67-72.

18 Young ID, Williams EM, Newcombe RG. Down syndrome and maternal age in South Glamorgan. $J$ Med Genet 1980;17:433-6.

19 Lesi FEA. A study of congenital malformation in newborn in Lagos, Nigeria. PhD thesis, University of Dublin, 1968.

20 Robinson A, Goad WB, Puck TT, Harris JS. Studies on chromosomal non-disjunction in men. Am J Hum Genet 1969;21:466-85.

21 Harlap S. A time series analysis of the incidence of Down's syndrome in West Jerusalem. Am J Epidemiol 1974;99: 201-7.

22 Stoller A, Collmann RD. Incidence of infective hepatitis followed by Down's syndrome nine months later. Lancet 1965;2:1221-3.

23 Uchida IA. Epidemiology of mongolism: the Manitoba study. Ann NY Acad Sci 1970;171:361-9.

Requests for reprints to Dr A A Adeyokunnu, Department of Paediatrics, University College Hospital, Ibadan, Nigeria. 